\title{
Debating Point
}

\section{On Talks}

\author{
IRVINE LOUDON*
}

What I have to say may be regarded as provocative or even insulting, but I think it needs to be said. In the history of medicine, a substantial number of lectures, seminars, and papers given at conferences and symposia-let's call them talks-are very difficult to follow, and a few are utterly incomprehensible. Very rarely is this because speakers have failed to master their subject. It is simply because of the way that talks are given. No doubt the same applies to other disciplines; but here I am concerned only with the history of medicine talks I have attended - the excellent, the good, the bad and the awful-during the last twenty or so years. And one thing has struck me again and again.

When I meet young historians informally and ask them about their research, almost invariably they describe what they are doing simply and clearly in colloquial terms. They know their subject. They are excited by it. They are keen to tell you about their research and do so without difficulty. Yet, when it comes to a seminar or a conference, the very same people produce a written text in which they bury their head, reading their paper as fast as they can as if terrified of not getting to the end in the allotted time. They seldom lift their head to glance at their audience. The pauses between sentences are imperceptible. Long and tortuous sentences, packed with provisos and subordinate clauses, bombard the mind like an artillery barrage. "Vogue" words, seldom if ever used in ordinary speech (epistemological seems now to be in fashion), are thrown in as a mark of the scholar, the professional historian. Some commit the cardinal sin of reading out statistics in sentences such as the following:

Between 1911 and 1913, in Warrington where the fertility rate was 120 the IMR was 175 whereas in Hull between 1909 and 1914, where the fertility rate was 90, the IMR was 109, and in Huddersfield and Leeds in 1905 it was over 130, in fact in Leeds it was 135 and I am sorry I meant to get the figures for fertility in Huddersfield and Leeds but I have not got them yet but they may be somewhere about 140 but I am not certain-so there you have the facts.

Nobody, but nobody, when such figures are read out at high speed, can retain them in their head for more than a few seconds, if at all.

In talks of this kind, where the speaker races through his or her text, it is usually possible to follow what is said for the first five or ten minutes. After that, with the best will in the world, the mind begins to wander. Mine does, anyhow. How long to coffee, lunch or tea? Will I be able to catch the early train or the next one? Who is the next speaker, and will he/she be as awful as this one? Eventually, one hears with relief that the

*Irvine Loudon, Medical Historian, The Mill House, Wantage, Oxfordshire, OX12 9EH.
I am grateful to Dr Stephen Lock and Dr Anthony Storr for advice and encouragement in writing this paper. 


\section{Irvine Loudon}

speaker has said "To sum up ..." only to continue at an accelerating pace for another twenty minutes.

What I have described is not an exaggeration, but the odd thing is the conspiracy of silence over such talks. Everyone pretends they have understood the whole paper. Criticism of the speaker is considered bad form, partly because it would be unkind, partly because of that old saying about living in glass houses, and partly because to admit you have failed to follow the talk is tantamount to a confession of inattention, ignorance, or stupidity. So the process goes on and bad speakers are left with the impression they have done well. Others, in the absence of criticism, are left with the belief that this is the way talks should be given.

This is not a trivial matter. The history of medicine is a rapidly expanding discipline. Its growth, its liveliness, and its interest are dependent not only on publications but also on the quality of talks and the subsequent discussion. Its worst feature by far is the abysmal quality of a substantial proportion of talks. Bad talks are profoundly depressing. Good talks, memorable talks, are immensely stimulating for they present you with new ideas and often prompt you to look at your own work in a new light. They are worth their weight in gold. So how can you avoid such pitfalls - and when I say "you" I mean "me, you, and everyone else" because I dislike the outmoded and tedious use of "one", as in "one ought to ..." or "one usually finds ...".

About forty years ago I was about to deliver my first talk to an audience. My father-inlaw* was an academic, famed for the brilliance of his lectures which he gave without so much as a note while strolling back and forth along the rostrum. He took me aside and warned me that most beginners talk far too fast when giving a lecture. You must never speak in a fast monotone; nor, on the other hand, should you speak in a slow monotone, because that will send the audience asleep. You should talk at a normal pace, but in short sentences with a perceptible pause-a considerably longer pause than you would use in ordinary conversation-between sentences. If you have a long sentence, break it up into parts and pause perceptibly between each section. This will allow your audience to assimilate what you have said and will put them on the alert to what you are going to say. next. You will hold their attention. That seemed to me then, and still seems to me now, to be excellent advice which opened my eyes to the fact that giving a talk is a public performance, and that the way to do it can be taught and practised.

There are various tricks. It is often useful when giving a talk to forget you are facing a crowd of academics, and imagine you are speaking to an old friend over a cup of coffeea friend you have not seen for some years who is working in a totally different discipline and wants to know what you are doing. You would use short, colloquial sentences, and plain everyday words. The same should apply to talks at a conference or any other occasion such as "work in progress". It is, to say it again, essential to realize that every talk is a public performance, although it should be a performance which comes across as unselfconscious and natural, not contrived or forced. And remember, if your audience cannot follow you, ninety-nine times out of a hundred it is your fault, not theirs.

Should papers be read, or should they be given from memory? There is nothing inherently wrong in reading a paper, provided you realize that writing a paper for a talk

*Professor F Norman (1897-1968), OBE, FSA. professor of medieval German, London University. 


\section{On talks}

and writing the same paper for publication are totally different activities. (Several times I have heard speakers, with no apparent sense of incongruity, say "As we saw above ..." or "As we will see below ....") This is a point of tremendous importance. If you have already written a thesis or a paper in a form suitable for publication, and you are asked to present your work at a seminar or conference, you have three choices. Talk with no notes at all. Talk with the aid of a few notes, using them as your main headings. Or write out in full a separate spoken version with much shorter sentences than the thesis or the paper for publication. In spoken papers it is not only permissible, but desirable to use the first person singular. You want to tell the audience this is what $I$ am going to talk about, these are the sources $I$ have used, these are the conclusions $I$ have reached, and so on. That is what the audience has come to hear. Leave out a lot of the detail of the published version. Stress the main features. Remember that although repetition is a sin in a published paper, it is not in a talk, where it is often useful to repeat some of the main points.

Having written a paper for delivery, read it out to yourself and time it. If it takes thirty minutes, it will —or should - take forty at the conference. Make sure you can say what you want to say in slightly less than the time allotted for your talk so that you can appear relaxed and unhurried. No audience is upset by a speaker who takes less than the allotted time, but the audience will be upset if you go on for too long. If you feel forty-five minutes is too short, listen to Alastair Cooke's broadcasts, 'Letter from America', which are not only exemplary models of how to talk, but vivid examples of how much ground can be covered in exactly fifteen minutes.

Reading a paper is perfectly acceptable provided the rules are followed. I know one very senior academic whose lectures are brilliant, but who cannot bring himself to give a lecture without writing it out in full and reading it. But he looks at the audience so frequently and his manner of delivery is so good, that you never guess he is reading rather than talking from brief notes. Many senior medical historians can do the same. But what about talking, with or without a few notes, rather than reading a paper?

It is astonishing to find how often this is regarded as a rare gift, acquired by only a few people of advanced age and great self-confidence. That is sheer nonsense. It is not difficult. Several years ago, I went to a talk by a young neonatal epidemiologist. Her background was nursing, and she was talking about maternal and child care amongst the Hutterite communities in North America, whom she had recently visited. This was not, at first sight, the most interesting subject in the world. She talked for three-quarters of an hour without a note, aided by a few graphs and photographs. It was an enthralling talk which had me and everyone else spellbound. I can still remember most of what she said, because she talked simply, easily and directly to the audience about what she had seen. A friend told me recently that he had gone to two talks on the new Globe Theatre, each fifty minutes long. One was given by a master carpenter, the other by an actor. Neither used a single note. "Both", said this friend, "were utterly enthralling. Why can't medical historians do the same?" I cannot remember any talks which were spoken rather than read-however technical or difficult-in which my attention wandered and which were not stimulating or enjoyable.

Speaking rather than reading is certainly the ideal. It produces a closer contact between speaker and audience. It leads to the use of colloquial English. It makes long convoluted sentences impossible. This can be seen when speakers who have read out a paper badly, 


\section{Irvine Loudon}

head down and at high speed, are asked questions in the discussion. Usually they answer clearly and comprehensively, using plain ordinary conversational speech, and I always feel like shouting: "If you can speak as well as that, why on earth did you not give your paper in the same manner?". Those who insist on reading a paper do so either because they believe it is the scholarly thing to do, or because of the universal fear of getting lost and drying up. To overcome this understandable fear, some rely on visual aids as their signposts. Others write out a few headings on cards or a single sheet of paper. Usually the act of writing is enough and speakers find they have given their talks without reference to their notes.

Illustrations-"visual aids"-should be used much more often than they are in the history of medicine because a visual message is a powerful reinforcement of the spoken word. The importance of presenting statistics as graphs or tables is too obvious to need stressing; and the rules should be well known. Yet within the last few weeks I have seen a senior historian show tables (apparently photocopied from a book or paper) in which the headings of the columns were invisible, and there were so many cells that only the front row could read them. They were incomprehensible. Like written text, tables designed for publication and tables designed for talks (which must be simple and large enough to read at the back of the room) are two different things.

Too little use is made of visual aids for names. Suppose that your talk contains a reference to the furious debate between Carl von Likowicz (1845-1910) and Julius Brekker (1837-1915) on the contagiousness of phthisis (don't look them up, I made them up). You, the speaker, will be thoroughly familiar with these two pathologists. Your audience will not. Display their names, dates, countries of origin and the institutions at which they worked. Leave them up on the screen as you talk. Do this even with household names like Pasteur or Koch or Lister. It is immensely helpful to the audience. If you display a quotation it should never be more than twenty or at most thirty words long. Never fall into the trap of turning to the screen and reading it out. Your audience is unlikely to be illiterate. Pause for long enough for the audience to read-and take in-the quotation.

There is another thing worth doing. Speakers often open their talks by saying "First I will talk about this, secondly about that, and thirdly about the other; and then I will sum up." It is indeed helpful to describe the structure of a talk, but you must remember that by the time you are well into the first part, most of the audience will have forgotten what the second and third parts are about. It is helpful to display them as headings on an overhead projector at the beginning, and ideally to show them again at the beginning of each section.

All that I am saying is this. Speaking, like other activities in the history of medicine, is a skill which can be taught but hardly ever is. Until recently oral history was thought of as something anyone can do because it is only talking to people and recording their answers. Nowadays, regular courses on oral history are held, and have been profoundly helpful to historians. I am told that many universities hold courses on how to give lectures, but I have never heard of a medical historian who has attended one, or of a Director of a Unit or department of history who has suggested such courses should be attended. The assumption that every postgraduate will have learnt how to give a talk by a process of undergraduate absorption is utterly false. We should acknowledge that talks are often 


\section{On talks}

badly given, and that this is a matter of concern for the health of the history of medicine. It is a disorder which can and should be cured. As a first step, postgraduates should be offered the opportunity to discuss and to learn the quite simple skills that can make all the difference between a good talk and a thoroughly bad one. If you have worked for months or years on a topic, it is mad to throw away the opportunity of presenting your findings in the best possible way, simply for want of instructions on how to give a talk. 